\title{
Pedagogical Supervision of Pupils as the Function of a Contemporary Form-master
}

\author{
Irina N. Andreeva \\ Natalia A. Biryukova \\ Elena V. Kondratenko \\ Lyudmila V. Kurochkina \\ Mari State University, Yoshkar-Ola, Russia \\ Email: kondratenko12@rambler.ru \\ Ksenia Yu. Badina \\ Gymnasium "Blue bird" named after T.V. Ishtrikova, Yoshkar-Ola, Russia \\ Email: vuk_2004@mail.ru
}

Doi:10.5901/mjss.2015.v6n3s7p27

\begin{abstract}
The aim of the research is to study different aspects in the pedagogical supervision of pupils within the framework of activities carried out by contemporary form-masters. The research included the use of the following methods: SWOT-analysis, pedagogical experiment, survey (interview, questionnaire), etc. The application of methods allowed us to find out the exact requirements to the readiness of a form-master to arrange the pedagogical supervision of pupils and to emphasize the most widespread difficulties that teachers face in the process of carrying out of this aspect of professional activities. The results of the research, touched upon in the article, show that the pedagogical supervision of pupils constitutes an important part of contemporary teachers' activities and allow applying a humanistic approach to the development of a pupil's personality. The authors of the article managed to distinguish the supervision peculiarities at different age of pupils and the most effective technologies of its implementation. Conclusion that is based on the results of the research proves the necessity of a purposeful and systematic preparation of a future form teacher during his education at University and the importance of analyzing physiological peculiarities of every age stage of pupil's development and acquiring of various pedagogical technologies while arranging pedagogical supervision.
\end{abstract}

Keywords: form teacher, pedagogical supervision, pedagogical technology, readiness of a form teacher to accomplish pedagogical supervision.

\section{Introduction}

In contemporary pedagogics, a supervision is defined as a special means of a pedagogical interaction in order to create favorable conditions for the development of subjects of interaction and forcing them to make optimal decisions in different situations of life choice (Slastenin, Kolesnikova, 2006). The stages of the pedagogical supervision might include diagnostics of the essence of the problem connected with the development, growing up and education or socialization of a personality; the search of the problem's solution, which is scientifically proved; the choice of optimal solution; the first assistance that should be offered at the first step of carrying out of the problem. An important role in accomplishing of the pedagogical supervision of pupils' development and their socialization belongs to a form-master. At a contemporary Russian school, a form-master is a teacher who arranges educational and pedagogical work in the form that is fiduciary for him. The institute of a form-master officially appeared in the 1870s in Russia, it was transformed several times and now its functions coincide with the institute of tutors in European education.

\section{Methodological Framework}

The process of the research was accomplished with the application of the following methods: systemic, humanistic, activity and person-oriented approaches. A systemic approach in the estimation of the pedagogical supervision reveals its 
multifold and multilevel character. On the assumption of the main provisions of the systemic approach, the functions that a form-master fulfills in the process of accomplishing the pedagogical supervision of pupils are as follows: analyticalforecasting, organizational-coordinative, communicative and monitoring.

The implementation of an activity approach in arranging of psychological and pedagogical supervision of pupils' development emphasizes common work of an adult and a child in which the leading role belongs to a form-master who is a monitor, adviser and assistant of a pupil in defining the further path of development (Bityanova, 1997).

Within the framework of person-oriented and humanistic approaches, it is possible to carry out an individual character of the pedagogical supervision of pupils' development, which are necessary to meet needs of self-development and self-understanding (Mudrik, 2000; Maslow, 1970; Rogers, 1961).

\section{Results}

Characterizing a contemporary form-master who accomplishes the pedagogical supervision in pupils' development at different age stages, we can mention that the main qualitative indicator of the activity is a competence, which is formed in the process of professional training and then during professional activities.

We carried out a questionnaire among young university pedagogical graduates of different faculties of Mari State University whose professional working experience is less than 3 years in order to find out difficulties that they have in accomplishing of the pedagogical supervision of pupils in the position of form-masters. We got the following results. 19,6 $\%$ of surveyed mention that that problems are mainly connected with establishing contact with pupils and maintaining interaction between them. $17,39 \%$ of surveyed experience difficulties in choosing techniques of the assessment of opportunities, needs of pupils, defining the structure and the development level of pupils' group. $15,21 \%$ of surveyed face challenges in conflict situations with pupils, their parents and other teachers; the same per cent have troubles when they should help pupils in the process of their professional self-determination.

Considering all competences of a future form-master that require oriented formation in the process of professional training of future teachers, we elaborated a model how to prepare future form-maters to accomplish the pedagogical supervision. This model includes three parts: theoretically methodological, substantially active and the model of results' assessment. This model was successfully approved during training of future teachers at Mari State University in 20112014.

Within the context of the pedagogical experiment, several tasks have been solved that allowed us to define pedagogical conditions of forming the readiness of future form-masters to accomplish the pedagogical supervision of pupils; to select and apply diagnostic methods that reveal the readiness of form-masters for this aspect of their professional activity; to elaborate the technological component of forming of the readiness of future form-masters to accomplish the pedagogical supervision. The majority of pedagogical technologies that were applied during the pedagogical experiment have interactive and contextual character and were oriented at involvement of future formmasters in the solution of problematic situations connected with the professional activity. Particularly, there was an application of such technologies as problematic education, technologies that help to arrange project activities, game technologies, technology of case-study, etc. (Birukova, Kondratenko, 2014; Kondratenko, 2012; Kurochkina, 2011).

As an experimental part of the research a special course has been introduced which is entitled "Form-master". The course was offered to bachelors of the $4^{\text {th }}$ year of education at the Historical-Philological Faculty, the Institute of Culture and Cross-cultural Communications, the Faculty of Physical Education, Sport and Tourism of the Mari State University that have the major in Pedagogical Education. The preparation of future form-masters for the accomplishment of the pedagogical supervision within the framework of this special course was focused on the formation of system of knowledge, skills which are necessary for the accomplishment of the pedagogical supervision and the enhancement of motivational sphere, value points, assessment and reflexive abilities of future form-masters. The aim of the course "Formmaster" was to acquaint future teachers with job responsibilities, tasks, assignments, functions of form-masters in contemporary school and to form and teach pupils the basis of the main technologies of educational activity.

Besides, we have revealed and diagnosed the following parameters of the readiness of form-masters to accomplish the pedagogical supervision of pupils: value and motivational, cognitive, activity, value and reflexive.

Value and motivational component in the structure of readiness of future form-masters to accomplish the pedagogical support of pupils is essential as it reflects the dynamics of the behavior of a future form-master who is encouraged by the aim, motifs, interests, intentions and striving for activities which show his direction in the process of accomplishing the pedagogical supervision. The context of this component includes the attitude to pedagogical supervision of pupils, intentions to establish connection between subject-to-subject interaction, striving for selfactualization and self-perfection in this kind of professional activities. The main criterion of the formation of the component 
is represented by the conscious attitude of a future form-master to the pedagogical supervision of pupils.

Cognitive component of the readiness is formed on the basis of value and motivational component as a result of cognitive activity of psychological, pedagogical and special knowledge about the essence of the pedagogical supervision. It is represented by the body of knowledge about the basis, peculiarities, methods and pedagogical technologies of arranging the supervision of different pupils' groups and characterized by the amount, deepness and system of knowledge about the essence of the pedagogical supervision, age peculiarities of the process accomplishment.

Value, motivational and cognitive components define the supervision of professional behavior of future formmasters which is represented in activity component of readiness. Responsible for the behavior, activity component of readiness constitutes a set of skills that is used by future form-masters on their way of achieving goals. Cognitive component of readiness of future form-masters for the pedagogical supervision is formed in the process of theoretical education (studying of psychological and pedagogical courses), while activity component is formed in the process of practical training by acquiring methods and technologies of educational work that are revised during the process of pedagogical practice. The criterion of the formation of activity component is practical readiness of future form-maters for the organization of the pedagogical supervision of pupils. Activity component of readiness consists of several professional skills: gnostic, constructive, project, organisational and communicative.

Value and reflexive component of readiness of a person for professional activity means the process of selfactualization and critical self-analysis of thoughts, activities which forms self-esteem the basis for which is the understanding of the activity itself. Value and reflexive component is final in the structure of the readiness for professional activity. Value and reflexive component of readiness of a form-master for the pedagogical supervision, education and socialization of pupils is reflected in the ability of future form-masters to access their activities comparing the achieved with expected results. The basis of an expected result constitutes the main aim of form-master's activity that is the creation of pedagogical efforts for personally oriented determination of pupils.

Pedagogical support of a form-master plays a significant role in the process of professional self-determination of pupils.

The form-master has the following tasks while accomplishing the pedagogical supervision in the process of professional self-determination of senior pupils:

- to create favorable psychological and pedagogical conditions to reveal potential opportunities and development of every pupil;

- to arrange systemic work of professional self-determination of pupils;

- to assist pupils in the choice of subjects for the basic and major levels in order to make up an individual educational program and supervise the control of how pupils acquire the programs of optional courses;

- to create conditions for self-actualization of pupils by arranging project and research activity, system of common creative events, organize different types of activities in which pupils may show their abilities;

- to create conditions for self-actualization of professional interests, intentions, opportunities of pupils and assist them in their self-actualization;

- to take part in useful public labour of pupils;

- to encourage pupils' participation in special clubs and optional courses;

- to acquaint systematically pupils with professions that are of high demand in the region;

- to establish and maintain contacts with organizations and establishments that carry out professional orientation of pupils;

- to coordinate actions of teachers who work with the class;

- to collaborate with pupils' parents;

- to help pupils in defining the place of future studies;

- to find out pupils' dissatisfaction of the life choice.

The aims of the supervision of a form-master include: to study peculiarities of every school pupil, to reveal his inner potential, formation of readiness of every pupil for the profession chosen, to assist in the process of a person's development. Therefore this activity us socially oriented and is carried out only by joint efforts of a teacher and a pupil that create conditions for self-actualization of a pupil. The supervision might be accomplished in close collaboration with a teacher-psychologist, teachers of certain subjects and teachers of additional education, pupils' parents, social and educational partners and others (Birukova, 2011)

The tasks of a form-master depend on age peculiarities of pupils. A more important role in pupils' life belongs to the form-master in primary school where s/he is almost the only teacher of different subjects and seems to be "the second mother". A move from kindergarten and primary school is associated with several difficulties which are mainly connected with mental and psychological load. In order to make such load less tangible, it is important to follow 
succession between different steps of education, thus, have a common system of education. The Federal State Educational Standard of primary education is also directed at providing succession of the main educational programs of pre-school, primary and secondary school of general school education, junior professional, secondary professional and higher educational establishments (Vestnik of Education, 2009).

According to A. A. Leontiev, succession is located across the borders of different age stages or forms of education (kindergarten - school, school - higher educational establishment, higher educational establishment - post-graduate) and it is a common organization of all stages and forms withinh the framework of the system of education (Leontiev, 2003). The priority direction of new educational standards constitutes subject results of mastering the main educational program of primary general education taking into account the peculiarities of the contents of exact school subjects. The main role in teaching these sucjects belongs to the form-master (Andreeva, Nabiullina, 2014).

The move from primary school to secondary school is connected with new requirements of teachers on different subjects, inability to adapt quickly to different conditions, a bigger number of school subjects, which have a negative influence on the educational advancement of pupils of the $5^{\text {th }}$ form. From our point of view, a key role might be accomplished by the form-master who could continue to work with pupils both in primary and secondary school. As a teacher who knows his pupils well, he might help them relieve stress and overload in obtaining knowledge.

A form-master spends more time with children in primary school than in the middle and senior forms. Besides, s/he teaches the majority of all lessons in the class, s/he supervises extracurricular activities of pupils, arranges various topical class hours, events and s/he is responsible for the group of a prolonged day. Thus, pupils spend the majority of the day with their supervisor. The work of a supervisor in primary school must emphasize "spiritual and moral development and education of pupils" (Bulletin of Education in Russia, 2009).

A significant role of form-masters is seen in the organization of the pedagogical supervision of professional selfactualization of pupils. The aim of the pedagogical supervision of professional self-actualization of senior pupils is that pupils acquire knowledge about themselves, the world of professions, requirements for this or that profession, correlate their "I want", "I can", "It is necessary"; they might choose profession and forge a positive attitude to labour; willingness and desire to plan professional and life path.

The readiness of future form-masters for the pedagogical supervision of professional self-determination of senior pupils is defined as a stable integrative characteristic of the personality of a future form-master that is reflected in his awareness of social and personal importance of professional orientation, the presence of the aim to collaborate pupils in the process of professional self-determination, acquiring knowledge, the presence of personal traits that provide the solution of professional tasks and assessment of efficiency of personal activity while arranging the pedagogical selfactualization of senior pupils.

If we take into account the systemic approach, it is possible to define the following functions of the supervisor in accomplishment of the pedagogical supervision of professional self-actualization of senior pupils: analytical and prognostic, organizational and coordinative, communicative and controlling.

Thus, accomplishing analytical and prognostic function, the teacher examines and analyses individual peculiarities (temperament, the type of a character, character traits) of pupils, follows the dynamics of their development, coordinate the process of self-development of a pupil.

Organizational and coordinative function envisages the elaboration of the plan (program) of psychological and pedagogical supervision, organization of conditions for accomplishing professional tests, holding consultations with pupils' parents and teachers of certain subjects about professional self-actualization, encouragement and recording of various activities of pupils, assistance in the self-actualization of senior pupils and creation of deliberate choice of their profession, interaction with every pupil and the class as a whole.

Based on results of diagnostic research, the form-master draws a project and plans of future activities to carry out in order to supervise pupils in their professional self-actualization and s/he follows a corrective detection. In the practice, s/he uses the following methods: comparison, dialogue, discussion, analysis and planning of the activity. The contents of form-master's work includes such kinds of activities as psychological diagnostics, class hours that activate the process of professional determination, meeting with parents at which the questions of professional self-actualization are discussed and individual talks.

As senior pupils are mainly attracted by the outer side of the chosen profession, one of the most significant tasks of the form-master in collaboration with subject teachers is to create necessary conditions in which pupils will ty their forces during professional practice as well as during research activities. The more the pupil tries himself in different spheres of professional activities, the easier he will define the sphere of human activity in which he will feel comfortable. Thus, an activity and practical component of the readiness of senor pupils for professional choice constitutes an important part.

A communicative function is carried out through the establishment of contacts between the subjects of the 
educational process (pupils, their parents, and teachers) with the help of questions of professional self-determination of pupils, training of pupils in order to establish efficient interaction between people, assisting pupils in formation of professional qualities.

A controlling function of the form-master is fulfilled by means of assessing the results of the pedagogical supervision of pupils' professional self-actualization.

The analysis of the pedagogical experience in the accomplishment of the pedagogical supervision of pupils' selfactualization allows us to conclude that this process will be more effective if:

- professional self-actualization is regarded as a mechanism of personal development and the result of this development;

- actual age needs of senior pupils are taken into consideration, as well as contradictions that might arise in the process of their implementation;

- pedagogical work on professional self-determination of senior pupils that are based on personal approach: a pupil becomes an active subject of the process of professional self-actualization and makes vital decisions independently (choice of major, education and profession);

- lessons devoted to professional self-actualization are held; the aim of such lessons is to form personal readiness of pupils for the choice of the type and level of education after finishing general or secondary school.

\section{Discussion}

The results acquired in the process of research do not cover the whole range of issues of the problem under consideration. Possible directions of research might be a comparative analysis of Russian and European experience of the pedagogical development, education and socialization of a person, elaboration and approbation of effective models and technologies in arranging of the pedagogical supervision of pupils, etc.

\section{References}

Andreeva, I. N., Nabiullina, N. T. (2014). Requirements of Federal State Standard in Developing Orthoepic Skills in Primary School and Their Application in Contemporary Text Books on the Russian Language. Bulletin of Mari State University, 3 (15), 5-8.

Biryukova, N.A. (2011). Formation of Readiness of a Teacher for Innovative Activity in the Context of Social Partnership of the Institute of Higher Education and School. Bulletin of Moscow State Oblast University. Edition "Pedagogics", 1, 18-22.

Biryukova, N.A., Kondratenko, I.B. (2014). Pedagogical Conditions of Formation of General Cultural Competences of Future Teachers in the Process of Interactive Education. Theory and Practice of Social Development. 9, 62-64.

Bityanova, M.R. (1997). Organization of Psychological Work at School. Moscow: Sovershenstvo.

Federal State Standard of Primary General Education (2009). Bulletin of Education in Russia. 2, 44-73.

Kondratenko, E. V. (2012). Technology of Professionally Oriented learning in Higher Education. Yoshkar-Ola: MarSU. 280 p.

Kurochkina, L.V. (2011). Formation of Competence of a Future Form Master in the Sphere of Professional Orientation of Pupils. Professional Training of a Teacher under conditions of Modernization of Higher Education: Collective Monograph. Yoshkar-Ola: MarSU. 210-222.

Kurochkina, L.V., Chulkova, R.G. (2014). Form-master: Tutorial. Yoshkar-Ola: MarSU. 352 p.

Leontiev, A.A. (2003). Succession and Continuity of Education. Educational System "School 2100". Pedagogics of Common Sense: Collection of Articles. Moscow: Balass, Publishing House of RAO. 28-34.

Maslow, A. H. (1970). Motivation and personality. New York: Harper \& Row, 1970.

Mudrik, A.V. (2000). Social Pedagogics: A Course Book for Srudents of Pedagogical Institites / Ed. By V.A. Slastenina. 3rd. Moscow: Publishing House "Academia". 200 p.

Slastenina, V.A., Kolesnikova, I.A. (2006) Pedagogical Support of a Child in Education: tutorial for the students of higher educational establishments. Moscow: Publishing House «Academia». 288 p.

Rogers, C. (1961). On Becoming a Person: A Therapists View of Psychotherapy. Boston. 
